Revista Ibero-Americana de Ciências Ambientais

Ibero-American Journal of Environmental Science

Anais do Simpósio Interdisciplinar de Práticas de Produção

Agrícola e Conservação Ambiental - Jan 2017 - v.8 - n.1

\title{
Cultivo de espécies hortícolas para a segurança alimentar e nutricional de famílias assentadas em Terenos (MS), Brasil
}

Esta pesquisa teve como objetivo investigar o cultivo e consumo das espécies hortícolas e sua importância na segurança alimentar e nutricional das famílias da Comunidade Jacob Fransiosi do Assentamento Emerson Rodrigues em Terenos, Mato Grosso do Sul. A pesquisa exploratória foi quanti-qualitativa, utilizando metodologia de pesquisa-ação, observação e entrevistas. O assentamento é formado por três comunidades, totalizando 136 famílias. Foi implantado no ano de 2005 e é distante aproximadamente $40 \mathrm{~km}$ da capital do Estado. A pesquisa foi realizada com 14 famílias, compreendendo $35 \%$ das famílias da Comunidade Jacob Fransiosi. Verificou-se a média de 3,8 indivíduos por domicílio, que não se diferenciou da média nacional rural, mas foi maior que a média rural do Centro Oeste. O critério para estabelecer a segurança alimentar e nutricional permitiu avaliar em $50 \%$ as famílias que podiam ser consideradas em segurança alimentar, enquanto que $50 \%$ enquadravam-se em insegurança alimentar (EM QUAIS CLASSES E/OU NIVEIS?), dos quais 35,8\% em insegurança alimentar grave, 7,1\% em moderada e $7,1 \%$ em insegurança alimentar leve. Entre as famílias que tinham acesso a hortas domésticas observou-se significante consumo de hortícolas, com possibilidade de aumentá-lo, através do consumo de algumas frutas e hortaliças produzidas nos próprios quintais. Concluiu-se como necessário a proposição de políticas públicas que incentivem e subsidiem a produção para o autoconsumo das famílias assentadas na perspectiva de minimizar os problemas relacionados à insegurança alimentar destes sujeitos.

Palavras-chave: Assentamentos; Produção Hortícola; Qualidade de Vida; Autoconsumo.

\section{Backyards horticulture for food security and nutrition from the families settled in Terenos (MS), Brazil}

\begin{abstract}
This research had purpose to investigate the cultivation and consumption of horticultural species and its importance in food security and nutrition from the families of Jacob Fransiosi Community of Emerson Rodrigues settlement in the town of Terenos/Mato Grosso do Sul state. The exploratory research was quantitative and qualitative, using the action research methodology, observation and interviews. The settlement consists of three communities, totalyzing 136 families. It was established in 2005 and it is far about $40 \mathrm{~km}$ from the state capital. The resarch was done with 14 families, embrasing $35 \%$ of the families from the Community. It was noticed an average of 3.8 people per household and that was not different from rural national average, but it was higher than the rural Midwest average. The standard to establish the food security and nutrition allowed to evaluate $50 \%$ the families that could be considerate in food security, while $50 \%$ fitted in food insecurity, of which $35,8 \%$ in severe food insecurity, $7.1 \%$ moderate and $7.1 \%$ in light food insecurity. There was significant consumption of vegetables between the families that had access to horticultural, with possibility to increase it through the consumption of fruits and vegetables produced in their yards. It was concluded the need to propose public policies that encourage and subsidize the production for self-consumption of families settled, expecting to minimize the problems related to food insecurity of these subjects.
\end{abstract}

Keywords: Settlements; Horticultural Production; Quality of Life; Self-Consumption.

\section{Topic: Química Agrícola e Ambiental}

Reviewed anonymously in the process of blind peer
Received: 18/04/2016

Approved: 20/05/2016
Claudinéia Lerios de Oliveira

Universidade Federal da Grande Dourados, Brasil

http://lattes.cnpq.br/2332975059903704

Claudy.agronomia@gmail.com

\section{Santino Seabra Junior}

Universidade do Estado do Mato Grosso, Brasil

http://lattes.cnpq.br/4990974747534079

santinoseabra@unemat.br

Marney Pascoli Cereda

Universidade Católica Dom Bosco, Brasil

http://lattes.cnpq.br/1892208680810050

cereda@ucdb.br
Sandra Mara Alves da Silva Neves

Universidade do Estado de Mato Grosso, Brasi

http://lattes.cnpq.br/6430066425008976

ssneves@unemat.br
Referencing this:

OLIVEIRA, C. L.; SEABRA JUNIOR, S.; CEREDA, M. P.; NEVES, S. M. A. S.. Cultivo de espécies hortícolas para a segurança alimentar e nutricional de famílias assentadas em Terenos (MS), Brasil. Revista IberoAmericana de Ciências Ambientais, v.8, n.1, p.6-20, 2017. DOI: http://doi.org/10.6008/SPC2179-6858.2017.001.0001 


\section{INTRODUÇÃO}

Análise pioneira e clássica da problemática alimentar no contexto brasileiro foi realizada pelo geógrafo Josué de Castro, um dos fundadores da Organização das Nações Unidas para a Alimentação e Agricultura (FAO), enfocando o fenômeno da fome na década de 1930. Contudo, preocupações efetivas por parte do governo com a segurança alimentar surgiram pela primeira vez em 1986, visando definir elementos norteadores de uma proposta política de abastecimento alimentar. O foco na distribuição de alimentos limitava-se a avaliar o controle do estado nutricional dos indivíduos, sobretudo a desnutrição infantil, sob a égide da Vigilância Alimentar e Nutricional (M ALUF et al., 1996). Em 1993 foi criado o Conselho Nacional de Segurança Alimentar (CONSEA), que iniciou seu funcionamento em 2003, com caráter consultivo para assessoramento da Presidência da República na formulação de políticas e na definição de orientações que garantissem o direito humano à alimentação (CONSEA, 2010).

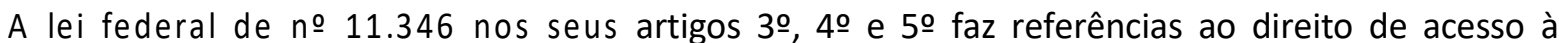
alimentação de qualidade para todos os indivíduos, seja através do acesso aos meios de produção ou por outras políticas que assegurem o direito alimentar e nutricional contribuindo para uma existência digna, em um contexto de desenvolvimento integral da pessoa humana (BRASIL, 2006).

Estudo da FAO alerta para os riscos da globalização na agricultura, destacando a atuação das multinaciona is nos mercados locais, pois estas limitam a capacidade de decisão dos agricultores (CAMARGO, 2002). Assim como a urbanização, a industrialização exerce grande influência no estilo de vida, na dieta e, consequentemente, no estado nutricional das pessoas (TARDIDO, 2006). Além da aquisição de alimentos, a produção própria pode ser relevante para a segurança alimentar, principalmente na área rural.

Pessanha (2000) enfatiza quatro fatores geradores de insegurança alimentar, a escassez da produção e da oferta de produtos alimentares, a distribuição desigual do direito de acesso aos alimentos na sociedade, a baixa qualidade nutricional e a contaminação dos alimentos consumidos pela população e a falta de acesso ou o monopólio sobre a base genética do sistema agroalimentar. O cultivo nos quintais é também, uma estratégia de garantir a segurança alimentar e tem relação com a agricultura familiar aliando fatores culturais e as necessidades objetivas que os agricultores têm em produzir alimentos para o autoconsumo ALTIERI (2009) afirma que os cultivos mistos garantem constante produção de alimentos e cobertura vegetal para proteção do solo, assegurando uma oferta regular e variada e, em consequência, uma dieta alimentar nutritiva e diversificada.

O quintal é um tema abordado em diversas pesquisas, com enfoque tanto no aspecto cultural quanto nos agronômicos, sendo considerado de grande relevância para a produção, segurança alimentar e nutricional e geração de renda (OAKLEY, 2004; NASCIMENTO et al., 2005; MONTEIRO et al., 2008; BEZERRA, 2009;).

Mota (2009); define os quintais como uma área agrícola de maior ou menor dimensão, localizado geralmente próximo à residência familiar, que desempenha um papel múltiplo, que compreende a produção de plantas medicinais, condimentares, aromáticas, ornamentais e o cultivo de plantas 
hortícolas.

As espécies hortícolas desempenham um papel essencial na dieta, caracterizando-se como complem entação alimentar por apresentarem vitaminas, proteínas e minerais, vitais para a manutenção da saúde e para com a segurança alimentar e nutricional (OAKLEY, 2004).

Dentre os alimentos consumidos com potencialidades funcionais, é imprescindível a contribuição das frutas e hortaliças, uma vez que estas contribuem com a maioria das vitaminas e minerais indispensáveis para o organismo. Assim, faz-se necessário consumir diariamente frutas e hortaliças para manter uma boa saúde e garantir uma alimentação equilibrada que propicie crescimento, desenvolvimento e manutenção das funções vitais, além de atuarem na prevenção de doenças. Afirmam ainda que a forma de cultivo das mesmas possui relação direta com a concentração de nutrientes (GÓES et al., 2008).

Uma das formas de garantir a segurança alimentar e nutricional é a implementação de políticas públicas e apoio à agricultura familiar, enfatizando alguns fatores primordiais como a oferta e acesso aos alimentos, a renda e à cidadania, apoio á adoção de práticas e técnicas de cultivo e processamento adequadas do ponto de vista sanitário pelos agricultores (PESSANHA, 2000) e a importância desta para a agrobiodiversidade.

Em estudo realizado através de um diagnóstico rural participativo no Loteam ento Ana Gonzaga no Rio de Janeiro foi identificada como principais motivações para o cultivo de plantas hortícolas nos quintais o fato de disponibilizar alimentos de qualidade, a importância do consumo para a manutenção da saúde dos indivíduos e o prazer/gosto de plantar como terapia ocupacional (MONTEIRO et al., 2004).

Além dos fatores destacados, pode-se associar como condição sine qua non para que ocorra a segurança alimentar e nutricional em assentamentos rurais, as políticas públicas que possibilitem aos assentados desenvolverem espaços de produção, na perspectiva de garantir a auto sustentação e a produção para a geração de renda, além da seguridade de todos os direitos sociais.

Face a argum entação exposta, nesta pesquisa buscou-se investigar o cultivo e consumo das espécies hortícolas e sua importância na segurança alimentar e nutricional das famílias da Comunidade Jacob Fransiosi do assentamento Emerson Rodrigues em Terenos, Mato Grosso do Sul. O clima da região onde se encontra inserido o município de Terenos é do tipo Tropical quente e úmido, cujos meses mais secos são junho, julho e agosto e os mais chuvosos, novembro, dezembro e janeiro. A precipitação varia de 1.500 a $1.750 \mathrm{~mm}$ anuais e são regulares, com período seco, inferiores a quatro meses, correspondendo a deficiência hídrica de 350 a $500 \mathrm{~mm}$ (NIMER, 1989). Sendo assim, os quintais são potencialm ente, um espaço estratégico de cultivo de alimentos indispensáveis à segurança alimentar e nutricional dessas famílias.

\section{METODOLOGIA}

A pesquisa foi realizada no período de julho de 2009 a m aio de 2010 na comunidade Jacob Fransiosi do assentamento Emerson Rodrigues, localizado no município de Terenos, Mato Grosso do Sul (Figura 01), distante $40 \mathrm{~km}$ da capital, Campo Grande. Na época da pesquisa o assentamento era composto por 136 famílias organizadas em três comunidades. A comunidade Jacob Fransiosi era formada por 40 famílias e 
estas estavam estruturadas em cinco núcleos de base, cada qual constituído por quatro a dez famílias. Destas foram sorteadas 14 famílias, representando $35 \%$ da população estudada.

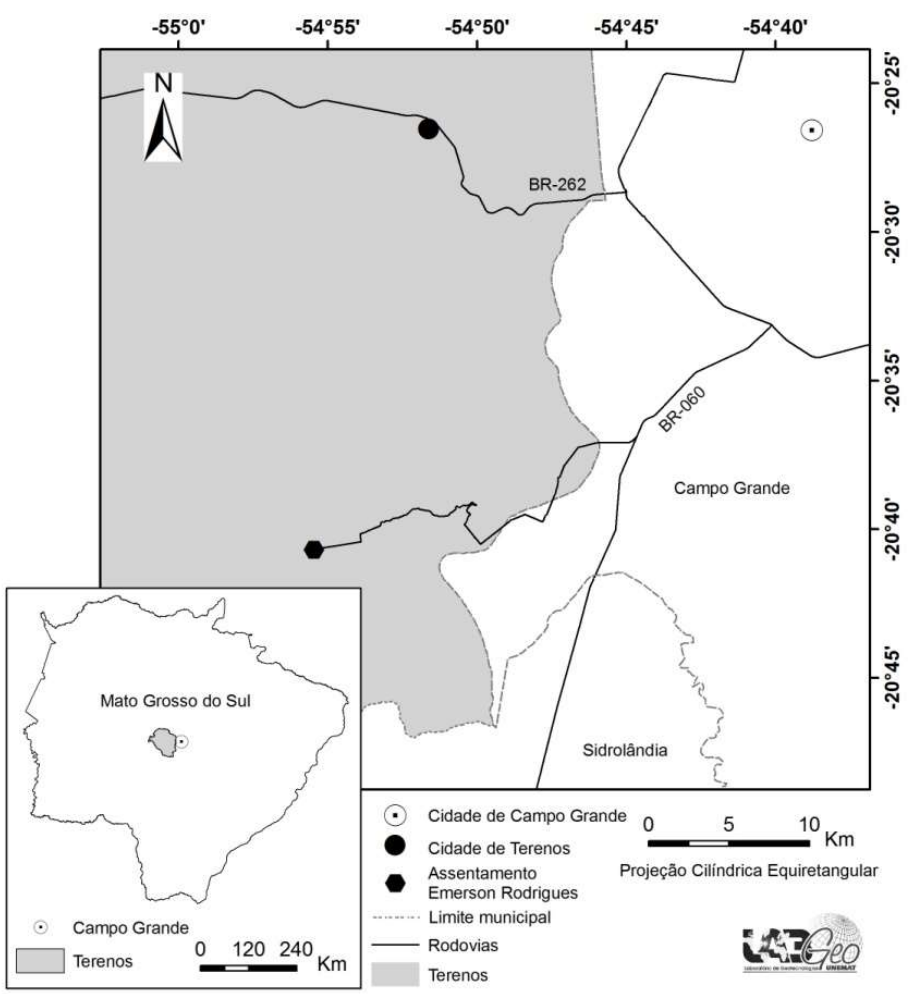

Figura 01: Assentamento Emerson Rodrigues em Terenos /MS. Fonte: Labgeo Unemat (2016).

O assentamento Emerson Rodrigues surgiu da unificação de três acampamentos, o Francisco Rosa, 08 de 0 utubro e Oziel Alves Pereira. As famílias destes três acam pamentos se reuniram em janeiro de 2006 na fazenda Santa Mônica e no dia 02 de dezembro de 2006 ocorreu o sorteio através do Incra ocorrendo assim a distribuição de lotes (Colocar a área) às famílias.

Após alguns meses foram liberados os recursos de Apoio Inicial destinado à instalação da rede de água e alimentação, e posteriormente aplicado o crédito fomento destinado à aquisição de ferramentas de trabalho, preparo de solo e compra de mudas frutíferas. $O$ acesso ao crédito de habitação ocorreu em seguida, (colocar o mês) através do qual foram construídas 60 casas da primeira etapa de construção.

O assentamento faz parte do complexo de assentamentos denominado Santa Mônica, composto por três assentamentos sendo eles; FETAGRI, Carlos Ferrari (CUT) e Emerson Rodrigues (MST). Foi realizada uma pesquisa exploratória quanti-qualitativa, com realização de entrevistas semi-estruturadas e estruturadas, além da observação da pesquisadora (THIOLLENT, 2003). A pesquisa foi direcionada aos indivíduos adultos responsáveis pela manutenção do quintal. Para estes, foram expostos os objetivos, os procedimentos metodológicos e a finalidade da mesma. Finalizada a exposição foi formalizada a adesão do informante pela assinatura do Termo de Consentimento Livre e Esclarecido.

A primeira fase da pesquisa caracterizou os informantes pelo uso de um questionário, destacando: a idade, gênero e escolaridade de todos os membros familiares por faixa etária. Posteriormente, foi caracterizado o consumo das frutas e hortaliças com as espécies consumidas, a forma de consumo, origem do alimento e frequência da oferta do alimento à fam ília, assim como 
a percepção da importância dessas espécies para a alimentação e saúde da família. Coletou-se dados sobre o cultivo de espécies hortícolas do quintal e também as informações para estabelecer o grau de segurança alimentar e nutricional.

A metodologia de pesquisa possibilitou a observação direta da realidade com intuito de complementar os dados coletados. Outros instrumentos também foram usados quando necessário tais como; caderno de campo para anotações das observações, desenhos de croquis e registros fotográficos, no sentido de auxiliar a discussão dos dados. A análise e interp retação dos dados coletados utilizou o programa R para cálculo de frequência absoluta ( $n$ ) e relativa (\%) (TAVARES, 2007).

Para a classificação das questões relacionadas à (in)segurança alimentar e nutricional realizouse a adaptação da proposta da Pesquisa Nacional por Amostra de Domicílio (IBGE, 2004), que tem como foco comunidades urbanas. Utilizou-se a metodologia de pontuação às perguntas: para as respostas negativas: atribuiu-se o valor "zero"; e para as respostas positivas: o valor "um", com um máximo de quatro pontos conforme a tabela 01 .

Tabela 01: Núm ero da questão, perguntas e pontuação das respostas contidas no questionário aplicado ao informante selecionado da Comunidade Jacob Fransiosi no Assentamento Emerson Rodrigues - Terenos/MS.

\begin{tabular}{|c|c|c|}
\hline № & Perguntas & Pontuação \\
\hline 01 & $\begin{array}{l}\text { Nos últimos três meses os moradores tiveram preocupação de que os alimentos acabassem antes de } \\
\text { poderem comprar ou receber mais comida. }\end{array}$ & $\begin{array}{l}\operatorname{Sim}(1) \\
\text { Não (0) }\end{array}$ \\
\hline 02 & $\begin{array}{l}\text { Nos últimos três meses os alimentos acabaram antes que os moradores tivessem dinheiro para comprar mais } \\
\text { comida. }\end{array}$ & $\begin{array}{l}\operatorname{Sim}(1) \\
\text { Não (0) }\end{array}$ \\
\hline 03 & Nos últimos três meses os moradores ficaram sem dinheiro para ter uma alimentação saudável e variada. & $\begin{array}{l}\operatorname{Sim}(1) \\
\text { Não (0) }\end{array}$ \\
\hline 04 & $\begin{array}{l}\text { Nos últimos três meses os moradores comeram apenas alguns alimentos que ainda tinham porque o dinheiro } \\
\text { acabou. }\end{array}$ & $\begin{array}{l}\operatorname{Sim}(1) \\
\text { Não }(0)\end{array}$ \\
\hline
\end{tabular}

Com relação à frequência de (in)segurança alimentar e nutricionais baseados nas perguntas sobre segurança alimentar e nutricional (Tabela 01) estas foram organizadas em categorias: Leve, Moderada e Grave. Cada uma das categorias foi subdividida em três níveis: baixa (B), média (M) e alta (A).

Para obtenção da pontuação foi classificada cada resposta referente à frequência em três subitens: resposta "não" (0 ponto); "em apenas 1 ou 2 dias" ( 1 ponto); “em alguns dias" (2 pontos); e "quase todos os dias" (3 pontos). Em seguida foram somadas as respostas, de acordo com o valor da pontuação, cujo total poderia chegar até o valor de doze pontos em cada categoria (Tabela 02).

Tabela 02: Classificação dos níveis de (in)segurança alimentar e nutricional utilizado no procedimento metodológico aplicado na comunidade Jacob Fransiosi, no assentamento Emerson Rodrigues em Terenos - MS.

\begin{tabular}{ccc}
\hline & Categorias & Grave \\
Leve & Moderada & 1 a 12 pontos \\
\hline
\end{tabular}

\section{RESULTADOS E DISCUSSÃO}

Verificou-se 32 espécies de fruteiras presentes nos quintais das 14 famílias da comunidade Jacob Fransiosi (Tabela 03). A manga foi citada por 78,57\% famílias na preferência de cultivo, porém é consumida por $21,42 \%$ delas. Pode-se inferir que o baixo consumo pode estar relacionado com o longo período de frutificação desta espécie. Há o caso de algumas espécies de fruteira que são cultivadas pelas 
famílias, porém não foram citadas como consumidas por não terem atingido o estágio de produção.

Pode-se observar que existem algumas espécies cultivadas em poucos quintais. Esta característica é uma especificidade da agricultura familiar tornando os quintais com um "campo de experim ento" sejam essas adaptadas ou não a região, por exem plo: a pera, a maçã, o pêssego, entre outras.

Tabela 03: Estatística descritiva do cultivo, hábito e origem das fruteiras cultivadas pelas famílias assentadas na comunidade Jacob Fransiosi do Assentamento Emerson Rodrigues em Terrenos/MS, ano de 2010.

\begin{tabular}{|c|c|c|c|c|c|c|}
\hline \multirow{2}{*}{ Espécies } & \multicolumn{2}{|c|}{ Frequência (\%) } & \multirow{2}{*}{$\begin{array}{l}\text { Hábito das } \\
\text { espécies }\end{array}$} & \multicolumn{3}{|c|}{ Origem } \\
\hline & $\mathrm{Fa}$ & $\mathrm{Fr}$ & & Familiar & Doação & Comprado \\
\hline Manga & 11 & 34,37 & Arbórea & 03 & 01 & 09 \\
\hline Laranja & 10 & 31,25 & Arbusto & - & - & 10 \\
\hline Limão & 10 & 31,25 & Arbusto & 02 & 01 & 07 \\
\hline Banana & 09 & 28,12 & Herbácea & - & 04 & 05 \\
\hline Mamão & 08 & 25,0 & Arbusto & 02 & 01 & 05 \\
\hline Caju & 08 & 25,0 & Arbórea & - & - & 08 \\
\hline Pocã & 07 & 21,87 & Arbusto & - & - & 07 \\
\hline Goiaba & 06 & 18,75 & Arbusto & 01 & - & 05 \\
\hline Acerola & 06 & 18,75 & Arbusto & 02 & - & 04 \\
\hline Coco & 06 & 18,75 & Palmeira & - & - & 06 \\
\hline Abacaxi & 05 & 15,25 & Herbácea & - & 02 & 03 \\
\hline Maça & 04 & 12,5 & Arbusto & - & - & 04 \\
\hline Maracujá & 04 & 12,5 & Trepadeira & 01 & - & 03 \\
\hline Tamarindo & 04 & 12,5 & Arbórea & - & - & 04 \\
\hline Carambola & 04 & 12,5 & Arbusto & - & - & 04 \\
\hline Abacate & 03 & 9,37 & Arbórea & - & - & 03 \\
\hline Pêssego & 03 & 9,37 & Arbusto & - & - & 03 \\
\hline Seringuela & 03 & 9,37 & Arbórea & - & - & 03 \\
\hline Laranja lima & 02 & 6,25 & Arbusto & - & - & 02 \\
\hline Melancia & 02 & 6,25 & Rasteira & - & - & 02 \\
\hline Jaca & 02 & 6,25 & Arbórea & - & 01 & 02 \\
\hline Amora & 02 & 6,25 & Arbusto & - & - & 01 \\
\hline Ameixa & 02 & 6,25 & Arbórea & - & - & 02 \\
\hline Pinha & 01 & 3,12 & Arbusto & - & - & 01 \\
\hline Lichia & 01 & 3,12 & Arbusto & - & - & 01 \\
\hline Caqui & 01 & 3,12 & Arbórea & - & - & 01 \\
\hline Figo & 01 & 3,12 & Arbusto & - & - & 01 \\
\hline Cajá & 01 & 3,12 & Arbusto & - & - & 01 \\
\hline Romã & 01 & 3,12 & Arbusto & - & - & 01 \\
\hline Conde & 01 & 3,12 & Arbusto & - & - & 01 \\
\hline Pitanga & 01 & 3,12 & Arbusto & - & - & 01 \\
\hline Pera & 01 & 3,12 & Arbusto & - & - & 01 \\
\hline Cajá-manga & 01 & 3,12 & Arbórea & - & - & 01 \\
\hline
\end{tabular}

Onde: Fa representa a quantidade de vezes em que as espécies foram citadas; Fr foi determinada em porcentagem.

Com relação às hortaliças, 23 espécies estão presentes nos quintais, sendo que as mais cultivadas foram: cebolinha, abóbora, salsa, quiabo e a alface (Tabela 04). A forma de consumo depende do tipo de hortaliça podendo ser através de saladas, cozida e frita. Destas espécies, apenas as abóboras não estão entre as mais consumidas, porém é uma das mais cultivadas, merecendo assim um aprofundamento na pesquisa.

Averiguou-se que as hortaliças folhosas são cultivadas em canteiros nas hortas cercadas, para evitar o ataque dos animais domésticos ou silvestres. As plantas perenes resistentes (quiabo, abóboras, jiló, etc.) são cultivadas em hortas de esforço mínimo, ou seja, cultiva-se em consórcio com as fruteiras ou próximas umas das outras, porém sem necessidade de regá-las para que possam produzir. 
Tabela 04: Estatística descritiva do cultivo, frequência absoluta e relativa em que as espécies foram citadas, hábito de crescimento das espécies, origem das hortaliças cultivadas pelas famílias assentadas na comunidade Jacob Fransiosi do Assentamento Emerson Rodrigues em Terenos/MS, ano de 2010.

\begin{tabular}{|c|c|c|c|c|c|c|c|c|c|}
\hline \multirow{2}{*}{ Espécies } & \multirow{2}{*}{$\mathrm{Fa}$} & \multirow{2}{*}{$\operatorname{Fr}(\%)$} & \multirow{2}{*}{$\begin{array}{l}\text { Hábitos das } \\
\text { espécies }\end{array}$} & \multicolumn{3}{|c|}{ Origem da espécie } & \multicolumn{3}{|c|}{ Forma de cultivo } \\
\hline & & & & Familiar & Doação & Comprado & Recipiente & Cova & Canteiro \\
\hline Cebolinha & 09 & 34,78 & Herbácea & 01 & 04 & 03 & 01 & - & 07 \\
\hline Abóbora & 08 & 34,78 & Herbácea & 01 & - & 06 & - & 07 & - \\
\hline Salsa & 07 & 26,08 & Herbácea & - & 01 & 05 & - & - & 06 \\
\hline Quiabo & 06 & 26,08 & Herbácea & 01 & - & 05 & - & 06 & - \\
\hline Alface & 05 & 13,04 & Herbácea & 01 & - & 02 & - & - & 03 \\
\hline Pimenta & 03 & 13,04 & Herbácea & 01 & 01 & 02 & - & 02 & 02 \\
\hline Couve & 03 & 13,04 & Herbácea & 01 & - & 02 & - & - & 03 \\
\hline Batata doce & 03 & 13,04 & Herbácea & 01 & - & - & - & 01 & 01 \\
\hline Cenoura & 02 & 8,69 & Herbácea & - & - & 02 & - & - & 02 \\
\hline Pimentão & 02 & 8,69 & Arbusto & - & - & 01 & - & - & 01 \\
\hline Maxixe & 02 & 8,69 & Herbácea & 01 & - & 01 & - & 02 & - \\
\hline Beterraba & 01 & 4,34 & Herbácea & - & - & 01 & - & - & 01 \\
\hline Coentro & 01 & 4,34 & Herbácea & - & - & 01 & - & - & 01 \\
\hline Batata inglesa & 01 & 4,34 & Herbácea & 01 & - & - & - & - & 01 \\
\hline Rúcula & 01 & 4,34 & Herbácea & - & - & 01 & - & - & 01 \\
\hline Almeirão & 01 & 4,34 & Herbácea & - & - & 01 & - & - & 01 \\
\hline Feijão de corda & 01 & 4,34 & Herbácea & - & 01 & - & - & 01 & - \\
\hline Tomate & 01 & 4,34 & Herbácea & - & - & 01 & - & - & 01 \\
\hline Cebola & 01 & 4,34 & Herbácea & - & 01 & - & - & - & 01 \\
\hline Pepino & 01 & 4,34 & Herbácea & - & - & 01 & - & 01 & - \\
\hline Caxi & 01 & 4,34 & Herbácea & - & - & 01 & - & 01 & - \\
\hline Jiló & 01 & 4,34 & Herbácea & - & - & 01 & - & 01 & - \\
\hline
\end{tabular}

Onde: Fa representa a quantidade de vezes em que as espécies foram citadas; Fr foi determinada em porcentagem.

No tocante ao consumo de frutas foram citadas 13 espécies pelas famílias, sendo que as mais consumidas foram: laranja, mamão, banana, maçã e limão, consumida de forma in natura, sucos e processamento de doce artesanal (Tabela 05$)$.

Tabela 05: Estatística descritiva do consumo, frenquencia absoluta e relativa em que as espécies foram citadas, forma de consumo e origem das frutas da com unidade Jacob Fransiosi do Assentam ento Em erson Rodrigues em Terrenos/MS, ano de 2010.

\begin{tabular}{l|c|c|c|c|c|c|c|c}
\hline \multirow{2}{*}{ Espécies } & \multicolumn{2}{|c|}{ Consumo (\%) } & \multicolumn{3}{c|}{ Forma de consumo } & \multicolumn{3}{c}{ Origem } \\
\cline { 2 - 10 } & $\mathrm{Fa}$ & $\mathrm{Fr}$ & Suco & In natura & Processado & Cultivado & Doado & Comprado \\
\hline Laranja & 11 & 84,61 & 07 & 06 & 0 & 05 & 00 & 06 \\
Mamão & 08 & 61,53 & 02 & 08 & 0 & 07 & 01 & 00 \\
Banana & 08 & 61,53 & 01 & 08 & 1 & 07 & 01 & 02 \\
Maça & 05 & 38,46 & 00 & 05 & 0 & 01 & 00 & 04 \\
Limão & 04 & 30,76 & 04 & 00 & 0 & 04 & 00 & 00 \\
Abacaxi & 03 & 23,07 & 01 & 03 & 0 & 02 & 00 & 00 \\
Manga & 03 & 23,07 & 01 & 03 & 0 & 03 & 01 & 01 \\
Acerola & 03 & 23,07 & 03 & 00 & 0 & 03 & 01 & 00 \\
Goiaba & 03 & 23,07 & 00 & 03 & 0 & 03 & 00 & 00 \\
Carambola & 02 & 15,38 & 02 & 01 & 0 & 02 & 00 & 00 \\
Tamarindo & 01 & 07,69 & 00 & 01 & 0 & 00 & 01 & 00 \\
Caju & 01 & 07,69 & 01 & 00 & 0 & 01 & 01 & 00 \\
Maracujá & 01 & 07,69 & 01 & 00 & 0 & 00 & 01 & 01 \\
\hline
\end{tabular}

Onde: Fa representa a quantidade de vezes em que as espécies foram citadas; Fr foi determinada em porcentagem.

A laranja é a fruta mais citada no índice de compra $(n=6)$, seguida da maçã. Esta compra pode estar relacionada com dois fatores distintos, que mesmo a laranja seja a fruta mais consumida, ainda assim precisa ser comprada devido à maior parte do cultivo no assentamento não atingir o estágio produtivo. A maçã tem origem do comércio devido não ser bem adaptada as regiões com temperaturas elevadas, ocasionando baixa produtividade, não atendendo então a demanda de consumo. 
O consumo da banana faz parte do hábito alimentar de $57,12 \%$ das famílias, destas $50 \%$ consomem a produção existente nos quintais. A banana e o mamão são as m ais cultivadas nos quintais por apresentar adaptação ao clima da região. Mesmo com as dificuldades impostas pelas condições climáticas a maçã está sendo cultivada em alguns quintais do assentamento. 0 limão consumido pelas famílias é produzido exclusivamente nos quintais do assentamento. Relativo às hortaliças constatou-se que 26 espécies são consumidas pelas famílias, com destaque para a cebolinha, apreciada por $85,71 \%$ dos entrevistados, na forma de salada e cozimento, sendo cultivada por $64,28 \%$ destas famílias (Tabela 06).

Tabela 06: Estatística descritiva do consumo, forma de consumo e origem das hortaliças da com unidade Jacob Fransiosi do Assentamento Emerson Rodrigues, em Terenos-MS em Terrenos/MS, ano de 2010.

\begin{tabular}{|c|c|c|c|c|c|c|c|c|}
\hline \multirow{2}{*}{ Espécies } & \multicolumn{2}{|c|}{ Consumo } & \multicolumn{3}{|c|}{ Forma de consumo } & \multicolumn{3}{|c|}{ Origem } \\
\hline & $\mathrm{Fa}$ & $\operatorname{Fr}(\%)$ & Salada & Cozido & Frito & Cultivado & Doado & Comprado \\
\hline Cebolinha & 12 & 46,15 & 08 & 09 & 0 & 09 & 02 & 01 \\
\hline Alface & 08 & 30,76 & 08 & - & - & 05 & 05 & 02 \\
\hline Quiabo & 07 & 26,92 & 01 & 05 & 06 & 07 & 01 & 01 \\
\hline Salsa & 07 & 26,92 & 07 & 01 & - & 06 & 01 & - \\
\hline Tomate & 07 & 26,92 & 06 & 01 & - & 03 & 01 & 04 \\
\hline Couve & 07 & 26,92 & 05 & 04 & - & 03 & - & 04 \\
\hline Cebola & 07 & 26,92 & 04 & 06 & - & 01 & - & 06 \\
\hline Alho & 06 & 23,07 & - & 06 & - & - & - & 06 \\
\hline Abobora & 05 & 19,23 & - & 04 & 01 & 05 & - & - \\
\hline Cenoura & 04 & 15,38 & 03 & 03 & - & 04 & - & 04 \\
\hline Batata doce & 03 & 11,53 & - & 03 & 03 & 02 & - & 01 \\
\hline Melancia & 03 & 11,53 & - & - & - & - & - & - \\
\hline Coentro & 03 & 11,53 & - & 03 & - & 01 & 01 & 01 \\
\hline Maxixe & 03 & 11,53 & 03 & 02 & - & 03 & - & - \\
\hline Batata & 02 & 7,69 & - & 02 & 01 & - & - & 02 \\
\hline Melão & 02 & 7,69 & - & - & - & - & - & - \\
\hline Beterraba & 02 & 7,69 & - & 02 & - & - & - & 02 \\
\hline Pimenta & 02 & 7,69 & - & 02 & - & 02 & - & - \\
\hline Pimenta do reino & 02 & 7,69 & - & 02 & - & - & - & 02 \\
\hline Pimentão & 02 & 7,69 & 01 & 01 & - & 02 & - & - \\
\hline Repolho & 02 & 7,69 & 01 & 02 & - & - & - & 02 \\
\hline Berinjela & 01 & 3,84 & - & 01 & - & - & - & 01 \\
\hline Serralha & 01 & 3,84 & 01 & - & - & 01 & - & - \\
\hline Jiló & 01 & 3,84 & - & 01 & - & - & - & 01 \\
\hline Rúcula & 01 & 3,84 & 01 & - & - & - & - & 01 \\
\hline Mangerona & 01 & 3,84 & - & 01 & - & 01 & - & - \\
\hline
\end{tabular}

Onde: Fa representa a quantidade de vezes em que as espécies foram citadas; Fr foi determinada em porcentagem.

Algumas hortaliças como o alho, tomate, couve e cebola estão entre os mais consumidos, porém uma parte significativa desses alimentos provém do mercado, pois, o alho não é uma hortaliça bem adaptada a região em questão; o tomate é uma espécie exigente em tecnologias de produção, sendo necessário o uso de agrotóxicos; as demais hortaliças citadas são bem adaptadas, mas, apresenta uma grande frequência de aquisição em mercados, o que implica em custos que em determinados períodos do ano são bastante elevados. Nessa ótica, a aquisição de alimentos no mercado pode ser um fator de restrição da dieta alimentar, ocasionando um estado de insegurança alimentar às famílias.

Há amplo conhecimento sobre a importância das espécies hortícolas por parte dos assentados no tratamento de doenças. A laranja foi indicada para o tratamento de cinco "doenças", seguida pela couve e a cenoura. Relativo às hortaliças, duas se destacaram pela suas múltiplas funções, a cenoura e a couve (Tabela 07). 
Tabela 07: Espécies hortícolas indicadas pelos entrevistados, com potencialidades para o tratamento e prevenção de doenças, parte do vegetal a ser utilizado e finalidade de sua utilização pelas fam ílias assentadas na comunidade Jacob Fransiosi do Assentamento Emerson Rodrigues em Terrenos/MS, ano de 2010.

\begin{tabular}{|c|c|c|}
\hline Espécie & Parte utilizada & Finalidade/utilização \\
\hline Cenoura & Fruto & $\begin{array}{l}\text { Utilizado no tratamento de pele } \\
\text { Tratamento de desnutrição infantil } \\
\text { Problema de visão }\end{array}$ \\
\hline Beterraba & Fruto & $\begin{array}{l}\text { Anemia } \\
\text { Tratamento de desnutrição infantil }\end{array}$ \\
\hline Banana & Fruto & $\begin{array}{l}\text { Osteoporose } \\
\text { Câimbra }\end{array}$ \\
\hline Salsa & Folha & $\begin{array}{l}\text { Diarreia } \\
\text { Dor de ouvido } \\
\text { Controle da hipertensão arterial }\end{array}$ \\
\hline Alho & Fruto & $\begin{array}{l}\text { Atua contra o vírus da gripe } \\
\text { Controle da pressão alta } \\
\text { Faz limpeza das vias arteriais }\end{array}$ \\
\hline Cebola & Fruto & Combate furúnculo \\
\hline Laranja & Fruto & Tosse \\
\hline Tomate & Fruto & $\begin{array}{l}\text { Controle do colesterol } \\
\text { Previne a gripe } \\
\text { Controle da pressão alta } \\
\text { Febre } \\
\text { Previne o câncer }\end{array}$ \\
\hline Alface & Folhas & Calmante \\
\hline Berinjela & Fruto & Baixa o teor de colesterol \\
\hline Maracujá & Fruto & Calmante \\
\hline Couve & Folhas & $\begin{array}{l}\text { Combate a anemia } \\
\text { Gastrite } \\
\text { Diabete } \\
\text { Atua contra problemas estomacais }\end{array}$ \\
\hline Abacate & Folha & Atua contra a tosse \\
\hline Limão & Fruto & Combate o vírus da gripe \\
\hline *Mangerona & Folha & Combate a diarreia \\
\hline Acerola & Folha & Combate o vírus da gripe \\
\hline Manga & Folha & Combate o vírus da gripe \\
\hline *Hortelã & Folha & Vermífugo \\
\hline
\end{tabular}

* Estas espécies são consideradas pelos entrevistados, como sendo medicinal ou hortícola, dependendo da forma de utilização.

A respeito do conhecimento de algum tipo de nutrientes presentes nos produtos hortícolas; $50 \%$ das famílias citaram a Vitamina C (Ácido Ascórbico) presente na laranja, 14,28\% a vitam ina C da ace rola e 7,14\% a vitamina C do limão. A couve foi citada por 7,14\% dos entrevistados como fonte de Vitamina $E$, e por conter fibras e $14,28 \%$ a citaram como fonte de Ferro. 0 tomate e a cenoura foram citados por $14,28 \%$ dos entrevistados como fonte de Betacaroteno e a banana de acordo com $7,14 \%$ como fonte de Potássio. Ao serem questionadas sobre a origem do aprendizado sobre o uso das frutas e hortaliças para o As análises dos dados relativos à segurança alimentar mostraram que 50\% das famílias entrevistadas encontram -se em estado de segurança alimentar e nutricional (SAN) e $50 \%$ vive em situação de insegurança alimentar, destes $35,8 \%$ estão em estado de insegurança alimentar grave, $7,1 \%$ em situação de insegurança alimentar moderada e 7,1\% em insegurança alimentar leve (Tabela 08).

Foram constatados que as famílias que estão em situação de segurança alimentar possuem renda não agrícola como: aposentadorias $(n=4)$, auxílio financeiro de parentes $(n=2)$ e comércio $(n=1)$. Assim, como $85,71 \%$ dessas famílias possuem poucos indivíduos por domicilio, de 2 a 4 pessoas. Portanto, os recursos não agrícolas contribuem na aquisição de alimentos, consequentemente na segurança 
alimentar.

Tabela 08: Categorias e níveis de (in)seguranças alimentar e nutricional em famílias da com unidade Jacob Franciosi no assentamento Emerson Rodrigues em Terenos/MS, ano de 2010.

\begin{tabular}{|c|c|c|c|c|c|c|c|c|c|c|}
\hline \multirow{3}{*}{ Famílias } & \multirow{3}{*}{ SAN* } & \multirow{2}{*}{\multicolumn{3}{|c|}{$\frac{\text { Leve } 1}{\text { Níveis }(1-12)^{* *}}$}} & \multirow{2}{*}{\multicolumn{3}{|c|}{$\begin{array}{c}\text { Moderada 2-3 } \\
\text { Níveis (1-12) }\end{array}$}} & \multirow{2}{*}{\multicolumn{3}{|c|}{$\begin{array}{c}\text { Grave } 4 \\
\text { Níveis (1-12) } \\
\end{array}$}} \\
\hline & & & & & & & & & & \\
\hline & & $\begin{array}{c}\text { B } \\
(1-4)\end{array}$ & $\begin{array}{c}M \\
(5-8) \\
\end{array}$ & $\begin{array}{c}A \\
(9-12) \\
\end{array}$ & $\begin{array}{c}\text { B } \\
(1-4)\end{array}$ & $\begin{array}{c}M \\
(5-8)\end{array}$ & $\begin{array}{c}A \\
(9-12) \\
\end{array}$ & $\begin{array}{c}B \\
(1-4) \\
\end{array}$ & $\begin{array}{c}M \\
(5-8)\end{array}$ & $\begin{array}{c}A \\
(9-12) \\
\end{array}$ \\
\hline 10 & $x$ & & & & & & & & & \\
\hline 20 & & & & & & & & & $X$ & \\
\hline 30 & & & & & $x$ & & & & & \\
\hline 40 & $x$ & & & & & & & & & \\
\hline 50 & $x$ & & & & & & & & & \\
\hline 60 & $x$ & & & & & & & & & \\
\hline $7 \underline{0}$ & & & & & & & & & $x$ & \\
\hline 80 & $x$ & & & & & & & & & \\
\hline 90 & & & & & & & & & & $x$ \\
\hline 10 은 & & & & & & & & & $x$ & \\
\hline 110 & & & & & & & & & & $x$ \\
\hline $12^{\circ}$ & $x$ & & & & & & & & & \\
\hline $13 ㅇ$ & $x$ & & & & & & & & & \\
\hline 140 & & $x$ & & & & & & & & \\
\hline
\end{tabular}

*SAN= Segurança alimentar e nutricional.

**Níveis= Os níveis foram determinados por meio de pontuação (1-12) dentro de cada categoria de SAN (Leve, Moderada e Grave), sendo que esta pontuação foi subdivida em três intensidades (Baixa, Média e Alta).

As famílias em situação de insegurança alimentar afirmaram utilizar fontes de renda basicamente da propriedade. Mas, outro fator observado foi que $80 \%$ dessas famílias são formadas por 5 a 7 pessoas por dom icílio. A quantidade de indivíduos por família associada à baixa renda agrícola pode ser um fator causal de insegurança alimentar.

Verificou-se que $86 \%$ dos indivíduos entrevistados possuem tradição no cultivo de plantas hortíco las, ou seja, o cultivo nos quintais das famílias entrevistadas não constitui um fator isolado. A dinâmica de cultivo modifica-se, pois alguns cultivam fruteiras distribuídas no entorno das moradias e hortas cercadas, para a produção de hortaliças folhosas. De acordo com Verheij et al. (2008), a produção de hortaliças e animais é muito atraente, portanto, há uma necessidade destes animais serem confinados em currais ou o cultivo de herbáceas e legumes será praticamente impossível e as hortas limitar-se-ão ao cultivo de plantas perenes resistentes. Para os autores os agricultores devem cultivar frutas de curta duração (como a banana, o mamão e o abacaxi) e os legumes anuais, sobrando mais tem po para dedicar na manutenção da horta.

Constatou-se que dos quintais investigados apenas dois possuíam apenas espécies frutíferas, distribuídas nos espaços próximos à residência, e não se observou a presença de hortaliças cultivadas. Os dem ais possuem espécies frutíferas em maior quantidade em relação às hortaliças. A ausência das hortaliças pode ser um fator de restrição da dieta alimentar e nutricional destes sujeitos por entender que as hortaliças produzem durante o ano todo, ao contrário da maioria das frutíferas que produzem em safras.

O cultivo de frutas e hortaliças no quintal em quantidade suficiente e, consequentemente, seu consumo, asseguram segurança alimentar e nutricional aos indivíduos em situação de vulnerabilidade, uma 
vez que o consumo de produtos hortícolas frescos é uma das únicas possibilidades de ter acesso a alguns nutrientes essenciais para o desenvolvimento humano como afirmam Nascimento et al. (2005) tornando-se indispensável o seu cultivo na área rural. Os produtos do quintal são praticamente a única fonte de retinol (vitamina A) e de ácido ascórbico (vitamina C) porque estas vitaminas se perdem facilmente quando estes alimentos sofrem algum tipo de processamento. Isso ressalta a importância do quintal como espaço de produção de alimentos as famílias, além de gerar renda com os excedentes de produção (MARCH, 1998 citado por NASCIMENTO et al., 2005).

A diversidade de espécies frutíferas é devido à destinação de parte do recurso do crédito Fo mento para aquisição de mudas, embora a quantidade de exemplares não seja suficiente para atender a demanda do consumo familiar.

As famílias que se encontram em situação de insegurança alimentar e nutricional cultivam em média 17 espécies hortícolas, apresentando maior diversidade que as famílias que se encontram em situação de segurança alimentar (14 espécies). Isso demonstra que as famílias que estão em estado de insegurança alimentar estão buscando alternativas de reverter essa situação através do cultivo de espécies alimentares. É necessário incentivar o cultivo de hortaliças devido ao ciclo serem curtos, e permitir vários cultivos durante o ano além de conter qualidades nutricionais semelhantes às frutas. A produção de frutas de ciclo mais curto e com produção constante também é uma alternativa para contribuir na segurança alimentar e nutricional desses sujeitos.

Verificou-se que $64,28 \%$ dos indivíduos pesquisados não utilizam insumos químicos no cultivo das frutíferas e hortaliças cultivadas nos quintais. Os tratamentos dados são à base de insumos orgânicos como: o húmus de minhoca, o esterco bovino, o extrato de neen, a calda de pimenta, a urina de vaca e a calda de fumo. Destes, as caldas foram as mais citadas pelos agricultores que utilizam controle alternativo. A água sanitária também foi citada por $14,28 \%$ dos agricultores como um método de controle alternativo de insetos das fruteiras e hortaliças.

o princípio ativo Methamidophos, pertencente ao grupo; Organofosforado, de classificação toxicológica; Extremamente Tóxico, foi citado por um agricultor, como utilizado para o controle de insetos nas frutas. Os demais não souberam informar o nome do agrotóxico que tem aplicado no controle dos parasitas. Neste caso, a preocupação com a contaminação ainda é maior, uma vez que ao desconhecerem o tipo utilizado impossibilita mensurar o grau de contaminação que os produtos podem causar no ambiente e nas pessoas.

A produção de frutíferas nos quintais, desde que seja planejada para proporcionar alimentos constantes e de qualidade aos assentados, pode ser uma alternativa de resistência destes agricultores à avalanche de alimentos industrializados, o que Ihes confeririam maior autonomia em relação ao mercado.

Por fim, para se garantir segurança alimentar e nutricional aos assentados se faz necessário repensar a produção para comercialização em detrimento a do autoconsumo, pois, de acordo com De Biase (2007): 
Os espaços do sítio que abrigavam a força de trabalho dedicada ao mercado ganham importância e dimensão em relação aos espaços diretamente relacionados ao bem-estar da família (fornecedores de alimento, medicamento, lazer, abrigo etc.). A atividade agrícola passa a dissociar produção e reprodução familiar, valorizando a primeira situação.

Ao analisar os dados dos indivíduos pertencentes às famílias pesquisadas, apresentados na Tabela 09, constatou-se que a idade média do grupo foi de 26,6 anos, embora o indivíduo mais idoso tenha declarado idade de 74 anos e que há maior representatividade na classe adulta, cujas pessoas possuem ida de entre 19 a 29 anos, com número significativo de indivíduos jovens entre os adultos. O que pode ser considerado como positivo as ao desenvolvimento das atividades produtivas.

Em média as famílias do assentamento são formadas em média por 3,8 pessoas, não diferenciando da média nacional rural, e sendo maior que a média rural do Centro Oeste, que é de 3,3 (IBGE, 2007), que tem como base produtiva no meio rural a produção em larga escala de grãos, altamente tecnificada e com baixo emprego de mão de obra.

Tabela 09: Distribuição dos assentados da Comunidade Jacob Fransiosi do Assentamento Emerson Rodrigues por faixa etária e domicílios em Terenos/MS.

\begin{tabular}{lllr}
\hline Classe & Faixa etária & Fa & Fr (\%) \\
\hline Crianças & $0-12$ & 13 & 24,07 \\
Adolescentes & $13-18$ & 09 & 48,14 \\
& $19-29$ & 11 & \\
Adultos & $30-39$ & 06 & 22,22 \\
Idosos & $40-49$ & 07 & 05,55 \\
\hline Total & $50-59$ & 05 & 100,0 \\
\hline & $>60$ & 03 & 21,4 \\
\hline $01-02$ & & 54 & 42,9 \\
$03-04$ & Número de pessoas por domicílio & 35,7 \\
\hline 04 & & 03 & 06 \\
\hline Total & & 05 & 100,0 \\
\hline
\end{tabular}

Fonte: Oliveira (2010). Onde: Fa representa a quantidade de vezes em que as espécies foram citadas; Fr foi determinada em porcentagem.

Averiguou-se que todas as crianças estão dentro da média escolar (Tabela 10). Dentre os adolescentes quase a totalidade possui ensino fundamental incompleto e baixo percentual relativo ao ensino médio seja completo ou incompleto, o que é ruim considerando que pela idade deveriam ter concluído o ensino médio. Há moradores em idade escolar que não está frequentando a escola. A situação do assentamento não possuir escola, exigindo que os alunos se desloquem $15 \mathrm{~km}$ de distância e os indivíduos que não estudam, mas com idade próxima a classe adulta, no contexto do assentamento tem a responsabilidade de ajudar no desenvolvimento das atividades produtivas do lote. Ambas as situações apresentadas podem constituir em fatores que estejam contribuindo para a situação apresentada a escolaridade na classe dos adolescentes. A situação tende a mudar com a estruturação do assentamento assegurada pelas políticas nacionais de educação, considerando que o assentamento se encontrava em processo de consolidação.

Os dados demonstraram que existe baixa escolarização entre os indivíduos pertencentes à faixa etária adulta (Tabela 10), pois apenas um mencionou estar estudando. Isto, associado à realidade dos 
jovens, demonstrou a necessidade de incentivos à educação de jovens e adultos no âmbito do assentamento, pois os conhecimentos escolares são fundamentais para desenvolvimento das atividades produtivas aos agricultores familiares.

Tabela 10: Distribuição dos indivíduos por faixa etária e grau de escolaridade dos entrevistados na comunidade Jacob Fransiosi no Assentamento Emerson Rodrigues em Terenos/MS, ano de 2010.

\begin{tabular}{|c|c|c|}
\hline Ano escolar & $\mathrm{Fa}$ & $\mathrm{Fr}(\%)$ \\
\hline \multicolumn{3}{|l|}{ Crianças de 05 a 12 anos } \\
\hline Ensino fundamental incompleto & 05 & 100 \\
\hline Ensino fundamental completo & 0 & \\
\hline Total & 05 & 100 \\
\hline \multicolumn{3}{|l|}{ Adolescentes de 13 a 18 anos } \\
\hline Ensino fundamental incompleto & 09 & 90 \\
\hline Ensino fundamental completo & 0 & \\
\hline Ensino médio incompleto & 01 & 10 \\
\hline Ensino médio completo & 0 & \\
\hline Total & 10 & 100 \\
\hline \multicolumn{3}{|l|}{ Adultos de 19 a 59 anos } \\
\hline Ensino fundamental incompleto & 29 & 87,8 \\
\hline \multicolumn{3}{|l|}{ Ensino fundamental completo } \\
\hline Ensino médio incompleto & 2 & 6,1 \\
\hline Ensino médio completo & 2 & 6,1 \\
\hline Total & 33 & 100 \\
\hline \multicolumn{3}{|l|}{ Adultos maiores de 60 anos } \\
\hline$>60$ & - & \\
\hline Não alfabetizado & 01 & 33,3 \\
\hline Ensino fundamental incompleto & 02 & 66,7 \\
\hline Total & 03 & 100 \\
\hline
\end{tabular}

Onde: Fa representa a quantidade de vezes em que as espécies foram citadas; Fr foi determinada em porcentagem.

Pertinente às profissões dos titulares dos lotes, praticada anteriormente ao assentamento, algumas tinham alguma ligação com atividades ligadas a terra, pois $22 \%$ eram agricultores, $7 \%$ arrendatário, $7 \%$ campeiro e $7 \%$ ajudante de pátio. As demais profissões estavam relacionadas às desenvolvidas no meio urbano, sem relação com espaço rural. Essas ocupações são caracterizadas como atividades braçais que provocam o desgaste físico, o que possivelmente influenciou na evasão escolar dos indivíduos da classe adolescente em idade escolar, que tinham a necessidade de trabalhar durante o dia e frequentar a escola durante o período noturno.

A maioria dos responsáveis pelos lotes $(85,71 \%)$ pertence ao gênero masculino, tendo estes, relação com a decisão para aquisição das mudas de espécies frutíferas e hortícolas, cujo assentamento se destaca na produção. Pois, de acordo com De Biase $(2007,10)$ "Diante da redução do território camponês, o espaço destinado à produção para o mercado (masculino) ganha importância em relação ao terreiro/quintal ou arredor de casa (feminino), e, portanto, adquire maior área relativa ao tamanho do sítio".

Com relação à origem, observou-se que os titulares se originam das várias regiões brasileiras (centro oeste, $35,71 \%$; sudeste, $28,57 \%$; nordeste, $21,42 \%$ e sul, $14,28 \%$ ), excetuando da região norte, fato este que influência na diversidade de plantas cultivadas nos quintais. As populações tradicionais são importantes no processo de cultivo e experimentação, devendo ser consideradas como mantenedoras da diversidade de várias espécies agrícolas (PEDROSO JUNIOR et al. 2008 citado por AMARAL et al., 2008).

As mulheres foram indicadas como responsáveis pelo preparo dos alimentos em cinco residências, 
os homens em quatro residências, em duas famílias ambos (homem e mulher), em um domicílio o preparo é de responsabilidade coletiva (homem e mulher e os filhos) e em uma família o genro é o responsável. Este resultado demonstrou a mudança no comportamento familiar referente à responsabilidade da alimentação, que principalmente junto às pessoas do campo, sempre foi atribuída ao gênero feminino. Heredia (1979) e Woortmann e Woortmann (1997) corroboram com exposto ao discorrerem que as relações sociais no meio rural estão associadas principalmente a atuação das pessoas da família em relação aos espaços que desempenham seu trabalho, nessa ótica de organização territorial, pertence ao homem os espaços de fora (a roça) e à mulher os espaços de dentro (a casa, incluindo os arredores da casa, quintal, terreiro, entre outros). Portanto, a mulher ao consumo (coleta e alimentação) e o homem a produção (caça, roçado e mercado).

\section{CONCLUSÕES}

O cultivo e o consumo de frutas e hortaliças podem contribuir na situação de (in)segurança alimentar e nutricional das famílias investigadas, mas a produção existente ainda é inferior a demanda do consumo.

É necessário haver incentivo à produção com efetiva contribuição de assessoria técnica para capacitar as famílias, principalmente aquelas que utilizam agrotóxicos, pois, podem estar se expondo ao risco de contaminação pelos pesticidas.

Há carência de políticas que proponham modelos de produção baseado no autoconsumo que contribuam na fixação do homem no campo, assim como, projetos para a formação/ampliação de pomares e hortas.

A situação de insegurança alimentar está relacionada com diversos fatores, como: renda familiar insuficiente proveniente da atividade agrícola e pecuária, família numerosa, poucas espécies hortícolas em estágio de produção e cultivo em quantidade insuficiente para atender a demanda familiar.

Os assentados em situação de insegurança alimentar grave não deixaram de cultivar espécies hortícolas, indicando a disposição e reação dos agricultores para superar os problemas que os afligem.

\section{REFERÊNCIAS}

ALTIERE, M.. Agricultura Campesina Sostenible: el Futuro del Planeta: Análisis, Posición y Plan de Trabajo de la Comisión de Agricultura Campesina Sostenible de La Vía Campesina. In: ENCUENTRO DE FORMACIÓN DE FORMADORES (AS) EM AGROECOLOGÍA, 1. Anais. Caracas, 2009.

AMARAL, C. N.; GUARIM NETO, G.. Os quintais como espaços de conservação e cultivo de alimentos: um estudo na cidade de Rosário Oeste (Mato Grosso, Brasil). Bol. Mus. Para. Emilio Goeld, Belém, v.3, n.3, p.329-341, 2008

BEZERRA, K. C.; SEABRA JUNIOR, S.; ABURAYA, F. H.; M APELI, N. C.. Cultivo de hortaliças em hortas domésticas nos quintais de Cáceres - MT. In: Jornada Científica da UNEMAT, 2. Anais. Barra do Bugres: UNEMAT, 2009.
BRASIL. Lei 11.346 de 15 de setembro de 2006. Cria o Sistema Nacional de Segurança Alimentar e Nutricional - SISAN com vistas em assegurar o direito humano à alimentação adequada e dá outras providências. Brasília, 15 de set. 2006.

CAMARGO, H. H. T.. Produção agrícola e alimentação tendências para o futuro. Revista de Informação Legislativa, v.39, n.155, p.321-326, 2002.

CONSEA. Conselho Nacional de Segurança Alimentar e Nutricional. A segurança alimentar e nutricional e o direito humano à alimentação adequada no Brasil: Indicadores e Monitoramento - da Constituição Federal de 1988 aos dias atuais. Brasília: CONSEA, 2010. 
DE BIASE, L.. A condição feminina na agricultura e a viabilidade da Agroecologia. USP Agrária, São Paulo, n.7, p.436, 2007.

GÓES, L. B.; DINIS, D. C. P.. Alimentos funcionais: uma alternativa Nutricional?. Cascavel: FAG, 2008.

HEREDIA, B. M. A.. A morada da Vida: trabalho familiar de pequenos produtores do Nordeste do Brasil. Rio de Janeiro: Paz e Terra, 1979.

IBGE. Pesquisa Nacional por Amostra de Domicílios - PNAD. Segurança alimentar 2004. Rio de Janeiro: IBGE, 2010.

MALUF, R.; MENEZES, F.; VALENTE, F.. Contribuição ao tema da segurança alimentar no Brasil. Revista Cadernos de Debate, Campinas, v.4, p.66-88, 1996.

MONTEIRO, D.; MENDONÇA, M. M.. Quintais na cidade: a experiência de moradores da periferia do Rio de Janeiro. Revista Agriculturas, v.1, n.0, p.29-31, 2004.

MOTA, M.. A produção agrícola dos pequenos quintais. Jornal de Sintra, maio, 2008.

NASCIMENTO, A. P. B.; ALVES, M. C.; MOLINA, S. M. G.. Quintais domésticos e sua relação com estado nutricional de crianças rurais, migrantes e urbanas. MultiCiência: Tecnologia para a saúde, Campinas, n.5, p.35-49, 2005.
NIMER, E. Clima. In: IBGE. Instituto Brasileiro de Geografia e Estatística, Diretoria de Geociências. Geografia do Brasil: Região Centro-Oeste. Rio de Janeiro: IBGE, 1989.

OAKLEY, E.. Quintais domésticos: uma responsabilidade cultural. Agriculturas, v.1, n.1, p.37-39, 2004.

PESSANHA, L.. A agricultura familiar e os quatro conteúdos da segurança alimentar. In: CONGRESSO OF RURAL SOCIOLOGY, 10. Anais. Rio de Janeiro: IRSA - SOBER, 2000.

TARDIDO, A. P.; FALCÃO, M.C.. O impacto da modernização na transição nutricional e obesidade. Revista Brasileira de Nutrição, São Paulo, v.21, n.2, p.117-124, 2006.

TAVARES, M.. Estatística Aplicada à Administração. Brasília: MEC, 2007

THIOLLENT, M.. Metodologia da pesquisa-ação. 12 ed. São Paulo: Cortez, 2003.

VERHEIJ, E.; WAAIJENBERG, H.. A horta de quintal nas regiões tropicais. Wageningen: Fundação Agromissa e CTA, 2008 .

WOORTMANN, E. F.; WOORTMANN, K.. O trabalho de terra: a lógica e a simbólica da lavoura camponesa. Brasília: EdUNB, 1997. 